\title{
Citrus aurantifolia impairs fertility facilitators and indices in male albino wistar rats
}

\author{
Uduak Akpan Okon*, Bassey Nyong Etim
}

\begin{abstract}
Department of Physiology, Faculty of Basic Medical Sciences, College of Health Sciences, University of Uyo, Uyo, Akwa Ibom State, Nigeria
\end{abstract}

Received: 8 July 2014

Accepted: 13 July 2014

\section{*Correspondence:}

Dr. Uduak Akpan Okon,

E-mail: chairmo2013@gmail.com

(C) 2014 Okon UA et al. This is an open-access article distributed under the terms of the Creative Commons Attribution Non-Commercial License, which permits unrestricted non-commercial use, distribution, and reproduction in any medium, provided the original work is properly cited.

\begin{abstract}
Background: The ability to reproduce is one of life's essential functions; therefore factors that affect this ability are of vital importance to mankind. We therefore designed this study to assess the effect of various dosages of $C$. aurantifolia treatment on fertility promoters and indices in male albino wistar rats.

Methods: Toxicity studies showed no lethality at $5000 \mathrm{mg} / \mathrm{kg}$. Eighteen male albino wistar rats weighing between 220 and $240 \mathrm{~g}$ were used. They were randomly assigned into three groups of six rats each. Group one served as control and was gavaged $5 \mathrm{ml}$ of normal saline, groups two and three were gavaged $1000 \mathrm{mg} / \mathrm{kg} \mathrm{and} 1500 \mathrm{mg} / \mathrm{kg}$ body weight as medium and high dose respectively twice daily for 21 days. On the $22^{\text {nd }}$ day, the rats were sacrificed and blood samples were obtained by cardiac puncture; following standard procedure, the serum was obtained for hormonal (FSH, LH, prolactin and testosterone) assay using microplate immunoenzymometric assay. The testes were harvested for semen analysis.

Results: LH level was significantly lower in medium dose $(\mathrm{P}<0.05)$ and high dose $(\mathrm{P}<0.001)$. A significant increase in medium dose and high dose groups $(\mathrm{P}<0.05)$ of testosterone levels when compared to the control group was observed. There was a significant decrease in fast progressive movement and percentage normal sperm morphology of sperm cells in medium dose and high dose $(\mathrm{P}<0.001)$. There was a significant decrease in percentage sperm concentration in medium dose $(\mathrm{P}<0.01)$ and high dose $(\mathrm{P}<0.001)$.

Conclusions: We therefore deduce that Citrus aurantifolia possess antifertility potentials in male albino wistar rats. Excessive intake should be with caution in males with fertility challenges.
\end{abstract}

Keywords: Fertility, Citrus aurantifolia, Semen analysis, Sex hormones, Male

\section{INTRODUCTION}

Fertility issues have been one of the major concerns of individuals, families and health-care givers. Studies have shown that more than $30 \%$ of fertility problems are male related factors. ${ }^{1}$ Several factors are known to interfere with fertility promoters and indices such as drug treatment, environmental toxins, air pollution and stress. Probably, other factors yet to be discovered still abound.

Citrus aurantifolia belongs to the genus of flowering plants in the family Rutaceace and it is a common edible fruit of this genus. The entire lime plant has been demonstrated to have a wide range of uses including: medicinal, industrial, cosmetic, pharmaceutical etc. ${ }^{2-6}$

The bioactive constituents of Citrus aurantifolia include: Flavonoid, limonoids, Alkaloids, Ascorbic acid, Tannins. ${ }^{7}$ Lime is readily available in every part of our society with its increasing social and medicinal uses by both men and women. For example, lime juice is used by women as a barrier contraceptive, and there is a reported history of African women douching with lime juice, lemon juice, vinegar or acidic soft drinks on the belief that it may prevent pregnancy and or sexually transmitted diseases. $^{8}$ 
Parameters to assess male fertility status include: semen analysis (sperm: motility, count, morphology, volume, fracture level and $\mathrm{pH}$ ) and hormonal assay ( $\mathrm{FSH}, \mathrm{LH}$, Testosterone and prolactin). The gonadotrophs and sex steroid hormones play cardinal role in spermatogenesis and by implication, facilitation of fertility status. For instance, FSH is responsible for initiation of spermatogenesis by inducing the proliferation of spermatogonia. ${ }^{9}$ Testosterone secretion from interstitial cells of Leydig is stimulated by Luteinizing Hormone (LH). Testosterone in turn sequences various stages of spermatogenesis. ${ }^{10}$

An in vitro study has shown that lime juice destroys both human immunodeficiency virus and sperm cells. The high acidity of the lime is suspected to be responsible for the destruction of the HIV and sperm cells. ${ }^{11-14}$ Another study showed that lime juice reduces the numbers of ova shedded and causes irregularity in the histology of the ovaries and uterus in female rats and may possibly affect fertility. ${ }^{15}$

Semen analysis evaluates certain characteristics and sperm content of the semen. It is performed to help in the assessment of male fertility status, for those with procreation challenges or for the verification of the success of vasectomy. Sperm count measures the concentration of sperm cells in the ejaculate. Over 15 million sperm per millilitres is considered normal. ${ }^{16}$ The World Health Organisation (WHO) has approved the value of $50 \%$ motility measured within 60 seconds of collection as normal. The WHO criteria for normal morphology as described in 2010 state that a sample is normal if $4 \%$ (or $5^{\text {th }}$ percentile) or more of the observed sperm have normal morphology. ${ }^{16}$ Semen volumes between $1.0-6.5 \mathrm{ml}$ are said to be normal. ${ }^{17}$

It has been reported that oligospermic or azoospermic patients with normal gonadotropins show relatively higher serum levels of prolactin, proving a role of prolactin in gametogenesis. ${ }^{18,19}$ There are many studies suggesting that hyperprolactinaemia has a definite role in the male infertility and is one of the reversible causes of infertility. ${ }^{19,20}$

In view of the foregoing, this study was therefore designed and conducted with the overall objective to assess the effect of various dosages of $C$. aurantifolia treatment on fertility promoters and indices in male albino wistar rats. The result of this study, we believe will provide further scientific information on the effect of consumption of $C$. aurantifolia by extrapolation in humans.

\section{METHODS}

\section{Plant material}

Fresh lime fruits were obtained from an early morning market in Uyo metropolis and were identified at the department of botany and ecological studies of the University of Uyo, Nigeria. The fruits were carefully washed to remove sand and dirt and sliced into two halves and was gently squeezed into a container. The obtained lime juice was filtered through a filter paper; the seeds and residual pulp were discarded. Fifty four lime fruits were processed in like manner, collected into a clean plastic vessel, covered and stored in the refrigerator. The $\mathrm{pH}$ of the lime juice was 1.7. A preliminary study was conducted on lethal dose $\left(\mathrm{L}_{\mathrm{D} 50}\right)$, and no lethality was recorded at $5000 \mathrm{mg} / \mathrm{kg}$.

\section{Animal preparation, experimental groupings and treatment}

Eighteen male albino wistar rats were used for this study. The animals were randomly assigned to three groups such that each group had six (6) animals. Group 1 served as the control group fed with normal rat chow (feed). Group 2 served as the medium dose group and were given 1000 $\mathrm{mg} / \mathrm{kg}$ glucose orally, twice daily. Group 3 served as the high dose group and received $1500 \mathrm{mg} / \mathrm{kg}$ Citrus aurantifolia orally, twice daily. All animals had access to water ad libitum. The cages were well ventilated, exposed to normal temperature and 12/12 hours light/dark cycle. After fourteen days of acclimatization, oral administration of lime juice to groups 2 and 3 commenced. The animals were sacrificed after 21 days. All experiments were examined and approved by the ethical committee of the University of Uyo on animal research and have therefore been performed in accordance with the ethical standards laid down in the 1964 Declaration of Helsinki.

\section{Sperm cell concentration}

Testes were crushed into pieces, diluted in $5 \mathrm{ml}$ of normal saline and allowed for 5-10 minutes to enable the spermatozoa to spread out into the diluents solution. $1 \mathrm{ml}$ of supernatant was diluted in $100 \mathrm{ml}$ solution. 0.01 of the suspension was loaded into a charged Neubauer counting chamber and cover slipped. It was allowed to rest for 10 minutes and observed microscopically. Number of cells were counted in millions $/ \mathrm{ml}$.

\section{Sperm morphology}

$1 \mathrm{ml}$ of seminal fluid was diluted with $20 \mathrm{ml}$ of buffered formol saline and then $0.01 \mathrm{ml}$ of the solution was loaded on a grease free slide with cover slip and viewed under a microscope and the following were observed: tail defect, neck defect, mid-piece defect, head defect and percentage of normal morphology was determined.

\section{Sperm motility}

$1 \mathrm{ml}$ of seminal fluid was diluted with $20 \mathrm{mls}$ of buffered formol saline and $0.01 \mathrm{ml}$ of the solution was loaded on a grease free slide and covered with a cover slip and observed microscopically. 


\section{Serum FSH, LH and prolactin measurements}

The FSH, LH and prolactin were determined based on the principle of sandwich method. The assay system utilizes a high affinity and specificity monoclonal antibody (enzyme conjugated and immobilized) directed against a distinct antigenic determinant on the intact FSH, LH and prolactin molecule. The test sample is allowed to react simultaneously with two antibodies, resulting in the FSH, $\mathrm{LH}$ and prolactin molecules being sandwiched between the solid phase and enzyme - linked antibodies.

After incubation, the wells were washed with washing solution to remove unburned labeled antibodies. Tetra methyl benzidine substrate is added and incubated, resulting in the development of a blue colour. The colour development is stopped with addition of stopping reagent, changing the colour to yellow. The concentration of FSH, $\mathrm{LH}$ and prolactin is directly proportional to the colour intensity of the test sample.

\section{Serum testosterone measurement}

Testosterone level is determined using competitive microplate enzyme immunoassay. Plates are coated with anti-testosterone antibodies. Calibrator specimen is first added to microplate well. Enzyme testosterone conjugate is added. Testosterone present in the sample competes with enzyme-testosterone conjugate for building with anti-testosterone counted microplate to form an antigenantibody complex. Unbound conjugate is removed by washing. The enzyme activity in the antibody-bound fraction is inversely proportional to the native testosterone concentration. The enzyme activity is revealed by colour change in tetramethylbenzidine substrate solution.

\section{Statistical analysis}

All results were presented as mean \pm standard error of mean. Three sets of data were analyzed using one way ANOVA, followed by the Least Significant Difference (LSD) procedure for significant $F$ values, $(P=0.05)$ was considered significant. Computer software SPSS and excel analyzer was used for the analysis.

\section{RESULTS}

\section{Comparison of FSH levels in different experimental group treated with Citrus aurantifolia}

Mean values of FSH level in control medium dose and high dose were mean \pm SEM, $0.12 \pm 0.02,0.02 \pm 0.02$ and 0.13 and $0.13 \pm 0.2$ respectively. There was no significant difference in FSH level, though a marginal increase was observed in the high dose (Figure 1).

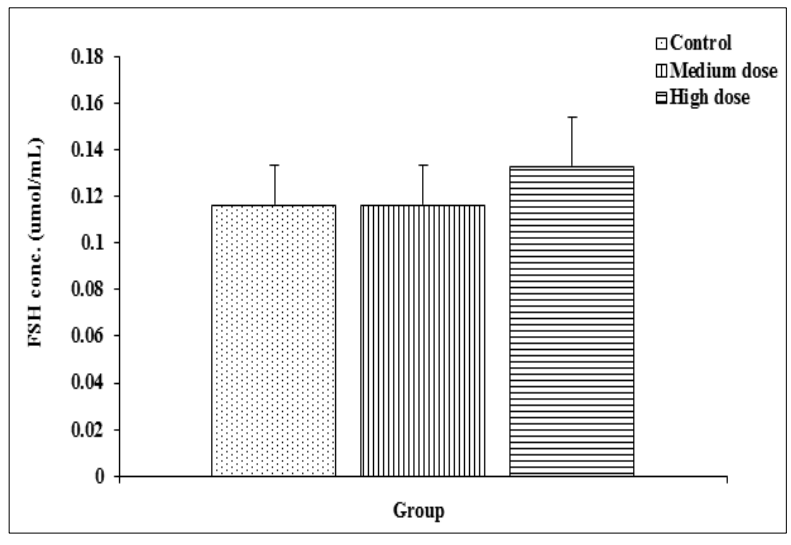

Figure 1: Comparison of follicle stimulating hormone (FSH) levels in different experimental groups treated with Citrus aurantifolia.

Values are expressed as mean \pm SEM, $\mathrm{n}=6$

\section{Comparison of LH levels in different experimental group treated with Citrus aurantifolia.}

Mean values of LH level in control medium dose and high dose were mean \pm SEM, $0.18 \pm 0.02,0.12 \pm 0.02$ and $0.10 \pm 0.00$ respectively. LH level was significantly lower in medium dose $(\mathrm{P}<0.05)$ and High dose $(\mathrm{P}$ $<0.001$ ) when compared to the control group (Figure 2).

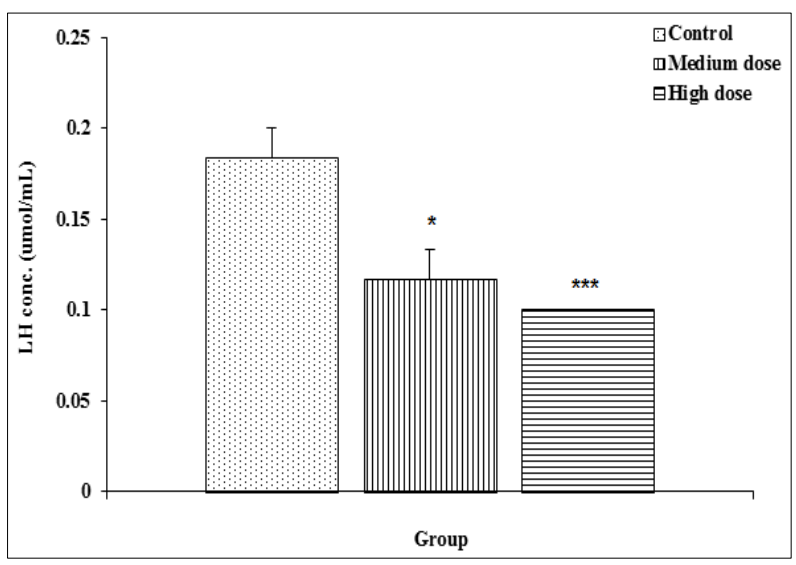

Figure 2: Comparison of luteinizing hormone (LH) levels in different experimental groups treated with Citrus aurantifolia.

Values are expressed as mean \pm SEM, $\mathrm{n}=6$

$* \mathrm{P}<0.05$, ***P $<0.001$ vs. control

\section{Comparison of prolactin levels in different experimental group treated with Citrus aurantifolia}

Mean values of LH level in control, medium dose and high dose were mean \pm SEM, $0.12 \pm 0.02,0.10 \pm 0.00$ and $0.10 \pm 0.00$ respectively. There was no significant difference in prolactin levels (Figure 3). 


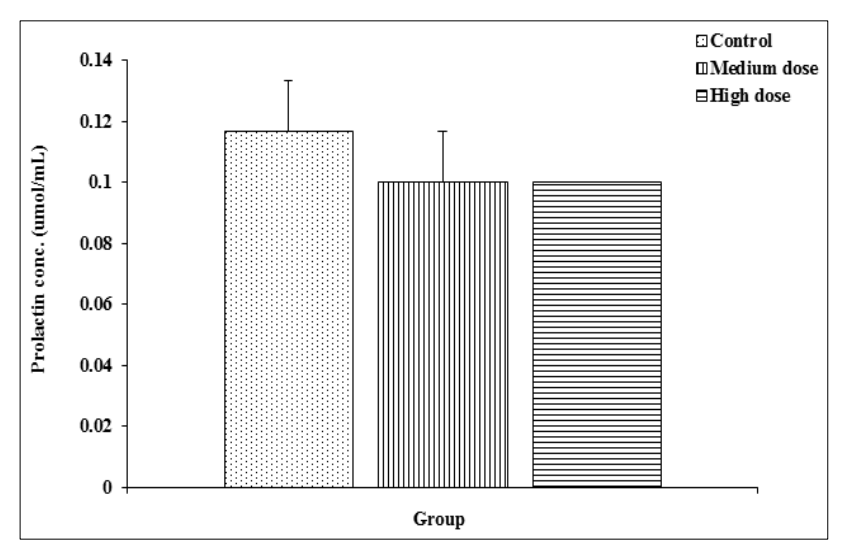

Figure 3: Comparison of prolactin levels in different experimental groups treated with Citrus aurantifolia.

Values are expressed as mean $\pm \mathrm{SEM}, \mathrm{n}=6$

Comparison of testosterone levels in different experimental group treated with Citrus aurantifolia

Mean values of LH level in control medium dose and high dose were mean \pm SEM, $8.12 \pm 2.01,28.63 \pm 7.81$ and $22.58 \pm 58 \pm 5.21$ respectively. There was significant increase in medium dose and high dose groups $(\mathrm{P}<0.05)$ when compared to the control group (Figure 4).

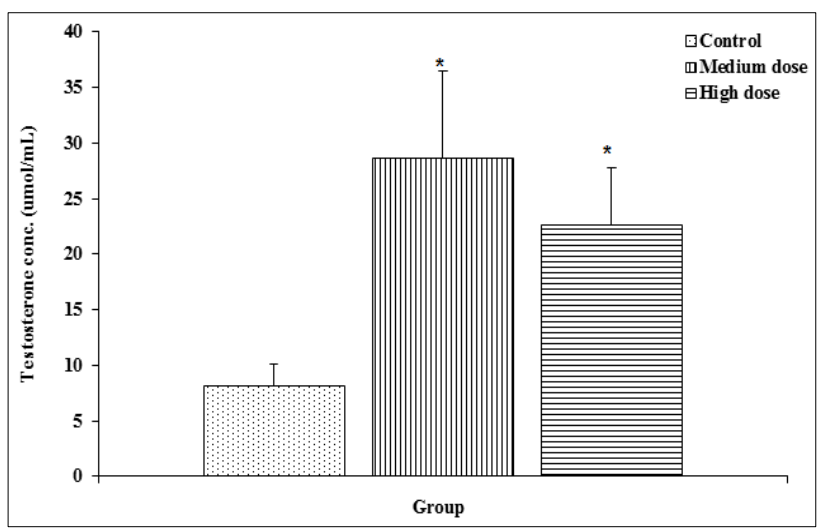

Figure 4: Comparison of testosterone levels in different experimental groups treated with Citrus aurantifolia.

Values are expressed as mean \pm SEM, $\mathrm{n}=6$

$* \mathrm{P}<0.05$ vs. control

Comparison of fast progressive movements (sperm motility) in different experimental group treated with Citrus aurantifolia

Mean values of fast progressive movements (sperm motility) in control, medium dose and high dose groups were, mean \pm SEM: $71.67 \pm 2.79,55.00 \pm 1.83$ and 54.33 \pm 1.48 respectively. There was a significant decrease in fast progressive movement of sperm cells in medium dose and high dose $(\mathrm{P}<0.001)$ when compared to the control group (Figure 5).

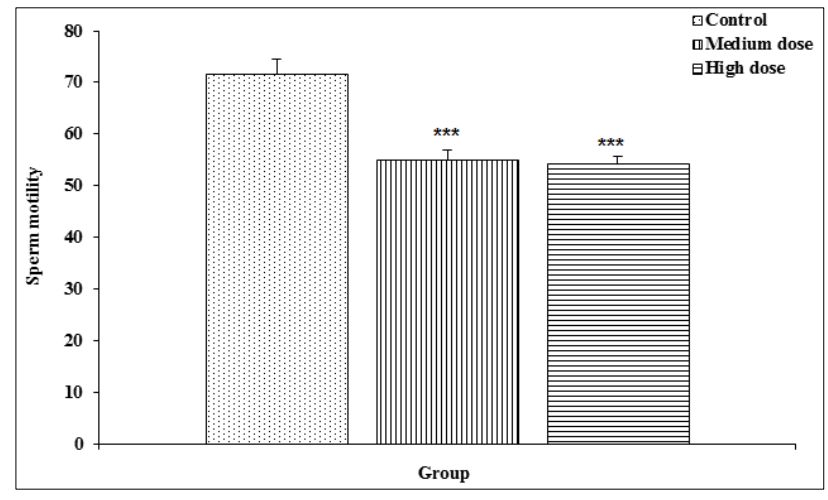

Figure 5: Comparison of fast progressive movement of sperm in different experimental groups treated with Citrus aurantifolia.

Values are expressed as mean \pm SEM, $\mathrm{n}=6$

$* * * \mathrm{P}<0.001$ vs. control

Comparison of percentage sperm concentration in different experimental groups treated with Citrus aurantifolia.

Mean values of percentage sperm concentration in control, medium dose and high dose groups were, mean \pm SEM: $69.67 \pm 2.08,61.33 \pm 1.52$ and $45.67 \pm 0.42$ respectively. There was a significant decrease in percentage sperm concentration in medium dose $(\mathrm{p}<0.01)$ and high dose $(\mathrm{P}<0.001)$ when compared to the control group. There was a significant decrease in percentage sperm concentration in the high dose $(\mathrm{P}<0.001)$ when compared to the medium dose (Figure 6).

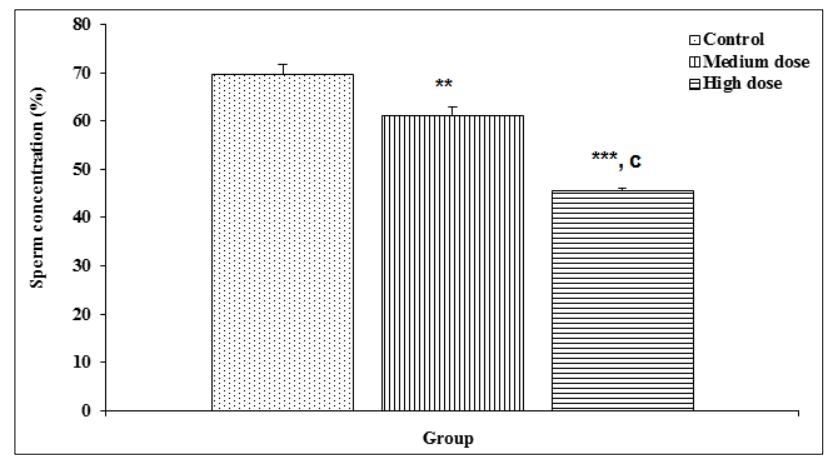

Figure 6: Comparison of percentage sperm concentration in different experimental groups treated with Citrus aurantifolia.

Values are expressed as mean $\pm \mathrm{SEM}, \mathrm{n}=6$

$* * \mathrm{P}<0.01, * * * \mathrm{P}<0.001$ vs. control; $\mathrm{c}=\mathrm{P}<0.001$ vs. medium dose

Comparison of percentage normal sperm morphology in different experimental groups treated with Citrus aurantifolia.

Mean values of percentage normal sperm morphology in control, medium dose and high dose groups were mean \pm 
SEM: $81.33 \pm 0.56,43.00 \pm 0.37$ and $54.67 \pm 0.92$ respectively. There was significant decrease in percentage normal sperm morphology in medium dose and high dose (P <0.001) when compared to the control group (Figure 7).

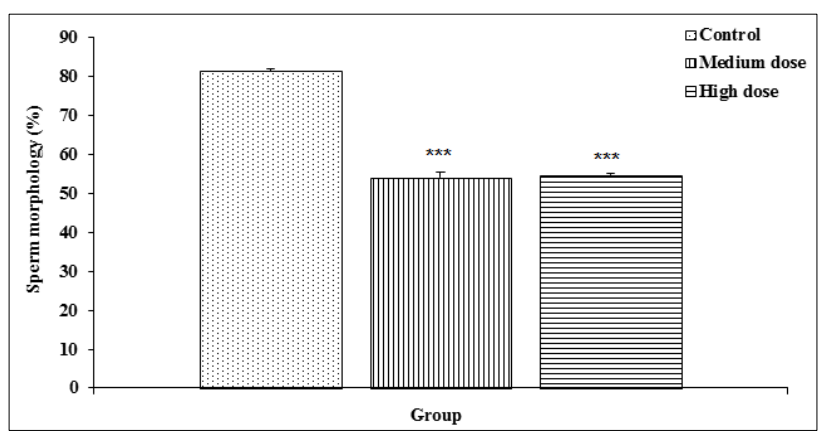

Figure 7: Comparison of percentage normal sperm morphology in different experimental groups treated with Citrus aurantifolia.

Values are expressed as mean \pm SEM, $\mathrm{n}=6$

$* * * p<0.001$ vs. control

\section{DISCUSSION}

Report from previous research study had indicated the anti-fertility effect of Citrus aurantifolia on estrous cycle and ovulation of Sprague-Dawley rats. ${ }^{21}$ The result from our study has further strengthened the need for caution in the indiscriminate consumption of lime juice especially in subject with fertility expectancy. Our findings assert the findings that Citrus aurantifolia does not only affect female rats reproductive process as previously reported but the male as well. This study has clearly demonstrated that Citrus aurantifolia is a potent inhibitor of fertility promoters and indices in male albino wistar rats. The result showed a dose dependent decrease in LH level and sperm concentration. Fast progressive movement of sperm and percentage normal sperm morphology were also significantly decrease by treatment with Citrus aurantifolia juice. There were no significant changes for FSH and Prolactin. However, testosterone showed a significant increase with both medium and high dosage administration of Citrus aurantifolia.

Sperm concentration, motility and viability are crucial indices that determine the potential of sperm to fertilize an ovum. Poor semen characteristic has been linked to damage spermatocyte DNA. ${ }^{22,23}$ It has also been reported that the integrity of spermatocyte DNA is protected by zinc and citric acid secreted from the prostate gland. ${ }^{24}$ The mechanism involves neutralization of reactive oxygen species. It is therefore most likely that certain phytochemical constituents of Citrus aurantifolia juice might have compromise either the normal secretion of zinc and citric acid by the prostate or interrupt an enzymatic pathway involve in reactive oxygen species deactivation. Hence, the resultant decreases in sperm quantity and quality.
In the male, an increase in prolactin level can cause a decrease in LH and testosterone levels resulting in low sperm concentration. LH is known to stimulate the interstitial cells of Leydig to synthesis and secrete testosterone. However, in this study, prolactin showed no significant changes though a marginal decrease was observed. This implies that, the decreased level of $\mathrm{LH}$ was not related to prolactin effect. The low LH concentration may therefore be due to the negative feedback signal triggered by rising testosterone levels as was the case in this study.

Present in Citrus aurantifolia as in most plants are biologically active macromolecules such as alkaloids, saponins, flavonoids, tannins, limonoids etc. How these active constituents selectively or synergistically contribute to the antifertility effect of lime juice is still a subject of interest for further research. Flavonoids in lime juice have been reported to exert mild anti-oxidative effects in lipid peroxidation. ${ }^{25}$ Limonoids are highly oxygenated modified triterpenes derived from a precursor with 4, 4, 8-trimethyl-17 furanyl steroid skeleton. ${ }^{26}$ Increasing body of evidence seems to suggest that limonoids and flavonoids have independent biological activities. ${ }^{27}$ Alkaloids are also major component of stimulant agents like cocaine, caffeine and nicotine. Studies have shown that exposure of human sperm to nicotine in vitro decreases the percentage of motile sperm. ${ }^{28}$ The alkaloid constituent has been implicated as responsible for this effect. As obtained from our result, the decrease in the percentage sperm motility in this study strongly supports these findings because Citrus aurantifolia is a rich source of alkaloids.

In an in vitro study, it was reported that about 2000 sperm cells were destroyed within 30 seconds of applying a quantity of lime juice and it was postulated that high acidity might have been responsible. Though we did not measure the $\mathrm{pH}$ of the lime juice administered in this study, previous study has earlier confirmed the low $\mathrm{pH}$ of lime juice. ${ }^{29}$ There was a dose dependent reduction in sperm motility, percentage sperm concentration and percentage normal morphology all pointing to the antifertility potency of lime juice, which is directly or indirectly related to its physico-chemical characteristics and phytoconstituent.

Findings from this study strongly demonstrate the antifertility potential of Citrus aurantifolia in male albino wistar rats. Almost all fertility promoters and indices including hormones and sperm quality and quantity were compromised. Excessive consumption should therefore be discouraged in males with fertility compromise.

\section{Funding: No funding sources \\ Conflict of interest: None declared}

Ethical approval: The study was approved by the University of Uyo Animal Research Ethics Committee in accordance with the ethical standards laid down in the 1964 Declaration of Helsinki 


\section{REFERENCES}

1. Isidori A., Pozza C, GianFrilli D, Isidori A. Medicinal treatment to improve sperm quality. J Reprod Biomed. 2006; 12:704-14.

2. Cooper TG, Nnonan E, Von Eckardstein. World Health Organization reference values for human semen characteristics. Reprod Update. 2010;(16):231-45.

3. Essing MG. Semen analysis, 2007. Available at: http://www.webmd.com/infertility-and-

reproduction/guide/semen-analysis. Accessed 30 April 2012.

4. Kokopelli Technologies. Adequate analysis frequency, 2007. Available at: http://www.fertilityformen.com/info_why.php.

Accessed 11 August 2007.

5. Weschler Toni. Fertility awareness method. In: Weschler Toni, eds. Taking Charge of Your Fertility. Revised ed. New York: HarperCollins; 2002: 189.

6. Boulpaep EL, Boron WF. Male sex act. In: Boulpaep EL, Boron WF, eds. Medical Physiology: a Cellular and Molecular Approach. 1st ed. St. Louis, Mo: Elsevier Saunders; 2005: 1125.

7. Peter Raven, George Johnson, Kenneth Mason, Jonathan Losos, Susan Singer. How Cells Harvest Energy and Photosynthesis. In: Peter Raven, George Johnson, Kenneth Mason, Jonathan Losos, Susan Singer, eds. Biology. 9th ed. New York: McGrawHill; 2010: 1279.

8. Bowen R. Gonadotropins: luteinizing and follicle stimulating hormones, 2004. Available at: http://arbl.cvmbs.colostate.edu/hbooks/pathphys/end ocrine/hypopit/lhfsh.html. Accessed 13 May 2014.

9. Karpas AE, Matsumoto AM, Paulsen CA, Bremner WJ. Elevated serum follicle-stimulating hormone levels in men with normal seminal fluid analyses. Fertil Steril. 1983;39:333-6.

10. Fox SI. Male reproductive system. In: Fox SI, eds. Human Physiology. 8th ed. Boston, MA: McGrawHill; 2004: 638-651.

11. Hair WM, Gubbay O, Jabbour HN, Lincoln GA. Prolactin receptor expression in human testis and accessory tissues: localization and function. Mol Hum Reprod. 2002;8(7):606-11.

12. Masud S, Mehboob F, Bappi MU. Severe hyperprolactinaemia directly depresses the gonadal activity causing infertility. Esculapio J Services Inst Med Sci. 2007;2:25-7.

13. Soler Fernandez JM, Caravacamagarinos F, Dominguez Bravo C, Murillo Mirat J, Aparicio Palomino A, Herrera Puerto J. Correlation of sperm prolactin, sperm count and motility. Prevalence of hyperprolactinaemia in the infertile male. Arch Esp Urol. 1990;43:891-5.

14. Dan Longo, Anthony Fauci, Dennis Kasper, Stephen Hauser, J. Jameson, Joseph Loscalzo. Alterations in sexual function and reproduction. In: Dan Longo, Anthony Fauci, Dennis Kasper, Stephen Hauser, J. Jameson, Joseph Loscalzo, eds. Harrison's Principles of Internal Medicine. 18th ed. New York: McGrawHill; 2011: 2887.

15. Mayo Clinic. Prolactinoma. In: Mayo Clinic, eds. Mayo Clinic Family Health Book. 4th ed. New York: Oxmoor House; 2009: 1448.

16. Buvat J. Hyperprolactenemia and sexual function in men: a short review. Int J Impot Res. 2003;15:373-7.

17. Mancini T. Casanueva FF, Giustina A. Hyperprolactinemia and Prolactinomas. Endocrinol Metab Clin North Am. 2008;37(1):67.

18. Berdanier C. Hormones. In: Berdanier C, eds. Advanced Nutrition; Macro Nutrients. 2nd ed. Boca Raton: CRC Press. 2000: 213-256.

19. Ivy JL. Role of carbohydrate in physical activity. Clin Sports Med. 1999;18:469-84.

20. Goodson SG, Qiu Y, Sutton KA, Xie G, Jia W, O'Brien DA. Metabolic substrates exhibit differential effects on functional parameters of mouse sperm capacitation. Biol Reprod. 2012;87(3):75.

21. Donald Voet, Judith G. Voet. Hormones. In: Donald Voet, Judith G. Voet, eds. Biochemistry. 3rd ed. Hoboken, NJ: Wiley \& Sons, Inc. 2004: 1361.

22. John Bray. Reproductive system. In: Bray J, Cragg P, Macknight A, Mills R, eds. Lecture Notes on Human Physiology. 4th ed. Hoboken, NJ: Wiley; 1999: 264-269.

23. Zini, A. Libman, J. Sperm DNA damage: importance in the era of assisted reproduction. Curr Opin Urol. 2006;16(6):428-34.

24. Agrawal A. Said TM. Role of sperm chromatin abnormalities in DNA damage in male infertility. Hum Reprod Update. 2003;9(3):341-5.

25. Mandkad M, Safhawara NG, Doshi H, Saiyed HN, Kumar S. Seminal plasma zinc concentration and alpha-glycosidase activity with respect to Semen quality. Bio Trace Elem Res. 2006;110(2):97-106.

26. Guyton A, Hall J. Body and control of the internal environment. In: Guyton A, Hall J, eds. Textbook of Medical Physiology. 12th ed. Philadelphia: Elsevier Inc.; 2006: 1003-1008.

DOI: $10.5455 / 2320-1770 . i j r \operatorname{cog} 20140949$

Cite this article as: Okon UA, Etim BN. Citrus aurantifolia impairs fertility facilitators and indices in male albino wistar rats. Int J Reprod Contracept Obstet Gynecol 2014;3:640-5. 